\title{
Longitudinal study of height and weight at adolescence
}

\author{
J M H BUCKLER AND J WILD
}

University Department of Paediatrics and Child Health, Leeds General Infirmary, Leeds

SUMMARY A longitudinal study through puberty of the height and weight of 96 boys and 102 girls in schools in and around the city of Leeds was conducted. Data for height and weight and height and weight velocities are presented, which are based on chronological age and on age relative to the age of peak height velocity. Comparison was made with the Tanner standards: male puberty developed a little later but growth continued longer, so that the adult men were taller and heavier. Girls showed a similar timing of puberty to the Tanner standards but were lighter at all ages and ultimately slightly taller as growth was not completed until later. It is important to know the pubertal state when interpreting growth changes in children.

In clinical practice much emphasis must be placed on reliable standards of normality in growth. The difficulties of obtaining standards that are up to date and appropriate for populations are very great especially for the years covering adolescence. Nevertheless, there is value in obtaining fresh data from time to time and relating these to previous standards. Twenty years ago Tanner, Whitehouse, and Takaishi produced outstanding papers that contained standards for height and weight, and they have been widely used.' ${ }^{1}$ The authors emphasised the importance of longitudinal data for adolescence, which is the period when the precise age of growth patterns varies greatly. The present longitudinal study, started in 1973, was undertaken to provide such information on children whose backgrounds were rather different from those reported by Tanner.

\section{Subjects and methods}

A single cohort of white schoolchildren (121 girls, 120 boys), without chronic disease, was recruited from seven day middle schools in and around Leeds. The schools chosen were selected because they would represent a cross section of social backgrounds and because staff support and cooperation could be expected. In response to a brief introductory notice about the proposed project interested parents with children in the appropriate year group (mostly 10 to 11 year olds) were invited to attend meetings at the schools and the full nature of the study was explained. It was emphasised that if a child entered the programme it was hoped that he or she would stay in it, although there was no obligation to do so. It became apparent that when the children progressed into adolescence their own willingness to continue participating lessened and five girls and six boys had to be excluded from the study because they withdrew at this stage. Children also withdrew at various stages of the project because they moved away or changed schools.

At the age of 13 the cohort went from the middle schools to many different high schools; in each of these the number of participants became relatively small and follow up much more difficult. A high proportion of pupils left school at the age of 16 years and though every effort was made to see them subsequently many were lost to follow up. Of those with whom contact was retained most could not continue to be seen at the same four monthly interval. Fortunately, most girls had almost completed their growth by the age of 16 so further follow up was not so crucial, but this was not the case with the boys.

The final analyses included only those children who were seen initially from an age when they were completely prepubertal, or in a small proportion (15 girls, two boys), in the earliest stage of puberty (Tanner stage 2 breast or genital development), and who were followed up until after the age of peak height velocity. ${ }^{2}$ Results are therefore presented on 96 boys and 102 girls.

MEASUREMENTS

Children were measured once a term, as close to 
four monthly intervals as possible and always within the range of three to six months. Repeat visits were often made to see previous absentees. The children were normally seen in the school 'medical' room. The measurements were made by one of us (JMHB) with the exception of pubertal ratings in the older girls which were evaluated by JW, who also recorded the results alongside previous records. The measurements were done without the observer knowing the previous values but were repeated if an error was suspected.

Height was measured according to the standard method of Tanner et al using a Harpenden anthropometer. ${ }^{3}$ The subjects were weighed with high quality bathroom scales (Krups, Republic of Ireland); in view of the recognised fluctuations in weight from hour to hour and day to day greater accuracy was regarded as unrealistic. ${ }^{4}$ Pubertal ratings were assessed according to the descriptions of Tanner in terms of genital development in boys, breast development in girls, and pubic hair in both sexes. $^{2}$ The age of onset of menstruation in girls was recorded. The first sign of puberty in boys was in most instances growth of the testicles to a size of 4 $\mathrm{ml}$ or greater (based on comparison with a Prader orchidometer).

\section{ANALYSIS OF DATA}

\section{Adjustments for missing or erroneous data}

Repeat visits were made to schools to see previous absentees, but for some of the measurements (76 of $2180(3 \%)$ for boys, 85 of $2179(4 \%)$ for girls) interpolated values were used as it was impossible to obtain measurements within six months of the previous ones. When subjects had left school, observations in many cases were reduced to once a year. Those still growing fast were followed up at the same intervals or not included after that age. In a minority ( 38 girls ( $37 \%), 22$ boys $(23 \%)$ ) in whom complete follow up was not possible but who (on the basis of constancy of consecutive height measurements when last seen or a rate equal to or less than
$1.5 \mathrm{~cm}$ over the last year) had clearly already effectively achieved adult stature, these last records for height and weight were extrapolated to the age of 17 years in girls and 18 years in boys.

Review of height measurements subsequently has shown a few values that were clearly mistakes (44 of $4261(1.03 \%)$ for height and 24 of $4261(0.56 \%)$ for weight), and appropriate corrected values have been assumed. In about half the instances corrections for height were only of the order of 2-5 mm. Most of the 'editorial procedures' were similar to those of the Swedish longitudinal study of $1976 .{ }^{5}$

\section{Centile distributions}

There was, of course, no uniformity in the actual chronological ages at which measurements were taken. A Fortran computer program was therefore used, which by interpolation between the values at known ages for each individual derived values for all subjects at the same half yearly ages. Thus for height and weight centile distributions could be determined over the age range 10 to 17 years for girls and 10 to 18 years for boys.

Weight and height velocities were calculated on a yearly basis - that is, taking every third measurement and dividing the increase by the exact time interval. The age at which the velocity is reported is midway between these two ages. Thus after the first year it was possible to calculate three velocities per year for each subject. The age of peak height velocity for a child (see below) was taken as the age where the maximum value occurred. Centile distributions of velocities were obtained in a similar manner to height and weight growth curves-that is, for each child velocities at half yearly intervals were interpolated by computer.

Centiles were also produced where the age axis was defined as age relative to age at peak height velocity. For each subject the age of peak height was determined as described above. Velocities were obtained by interpolation at half yearly intervals relative to this point.

Table 1 Duration of follow up measurements

\begin{tabular}{|c|c|c|c|c|c|}
\hline $\begin{array}{l}\text { Mean (SD) age } \\
\text { when first } \\
\text { seen }\end{array}$ & $\begin{array}{l}\text { No (\%) completely } \\
\text { prepubertal } \\
\text { when first seen }\end{array}$ & $\begin{array}{l}\text { Duration of } \\
\text { follow up in } \\
\text { years }(S D)\end{array}$ & $\begin{array}{l}\text { No }(\%) \text { seen } \\
\text { through the } \\
\text { age of } P H V^{*}\end{array}$ & $\begin{array}{l}\text { No }(\%) \text { seen } \\
\text { past the age } \\
\text { of menarche }\end{array}$ & $\begin{array}{l}\text { No (\%) seen } \\
\text { until fully } \\
\text { grown }\end{array}$ \\
\hline \multicolumn{6}{|c|}{ Boys $(n=96)$} \\
\hline $10 \cdot 10(0 \cdot 71)$ & $92(96)$ & $7.08(1.31)$ & $96(100)$ & & $54(56)$ \\
\hline \multicolumn{6}{|c|}{ Girls $(n=102)$} \\
\hline $9.68(0.66)$ & $87(85)$ & $6.60(1.59)$ & $102(100)$ & $98(96)$ & $69(68)$ \\
\hline
\end{tabular}

\footnotetext{
*Peak height velocity.
} 


\section{Results}

Over half the children were followed up until they were effectively of adult stature (table 1) and 98 of the 102 girls were past the age of menarche when last seen. The length of follow up is also shown in the table.

Centile curves are shown in figs $1-4$. The results are all presented with respect to chronological age and with respect to age relative to the age at peak height velocity. Fig 1 shows the height curves of the boys and girls, fig 2 shows the weight curves, and figs 3 and 4 show the corresponding velocity curves. The spread of the ages over which the various stages of puberty occurred in the present study compared with those of Tanner's data ${ }^{6}$ are shown in figs 5 and 6 for boys and girls, respectively.

The figures confirm the well recognised difference
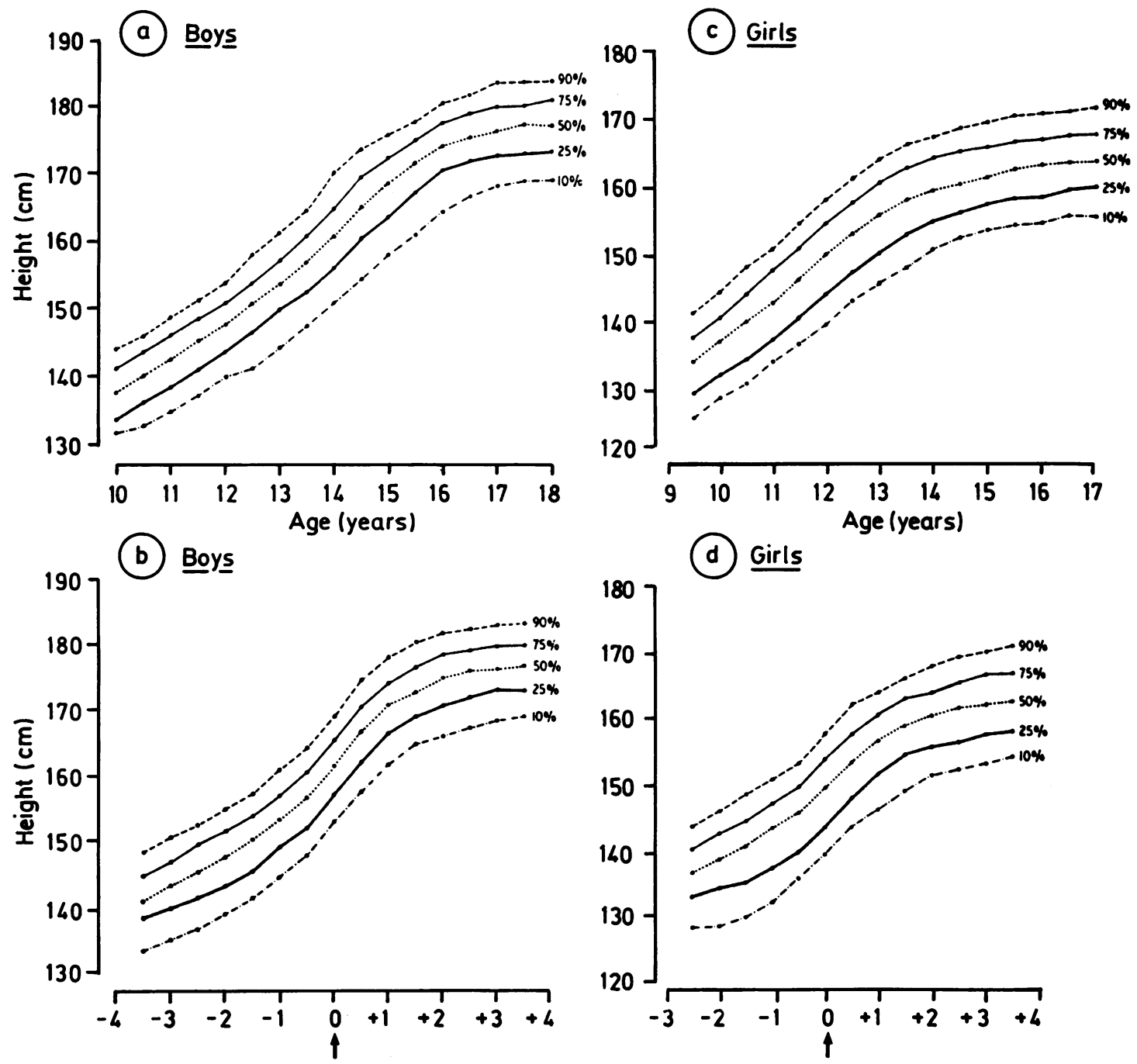

Age of peak height velocity

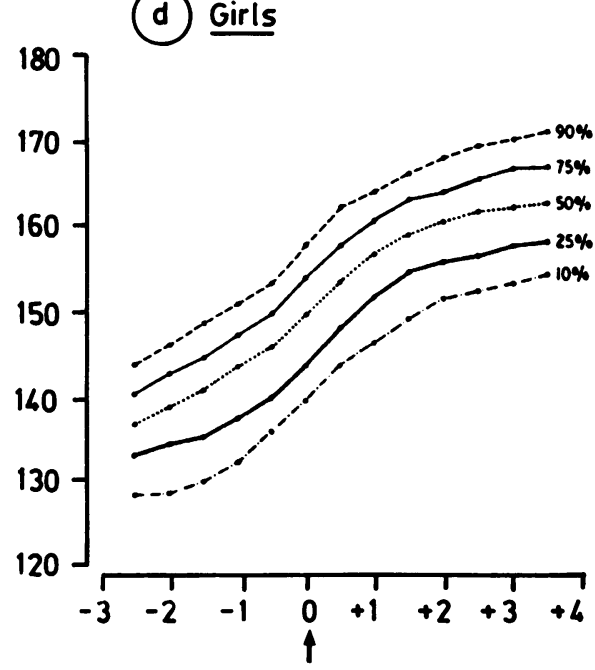

Age of peak height velocity

Fig 1 Centile curves for height for girls and boys; $a$ and $c$ with respect to age and $b$ and $d$ relative to the age of peak height velocity. 

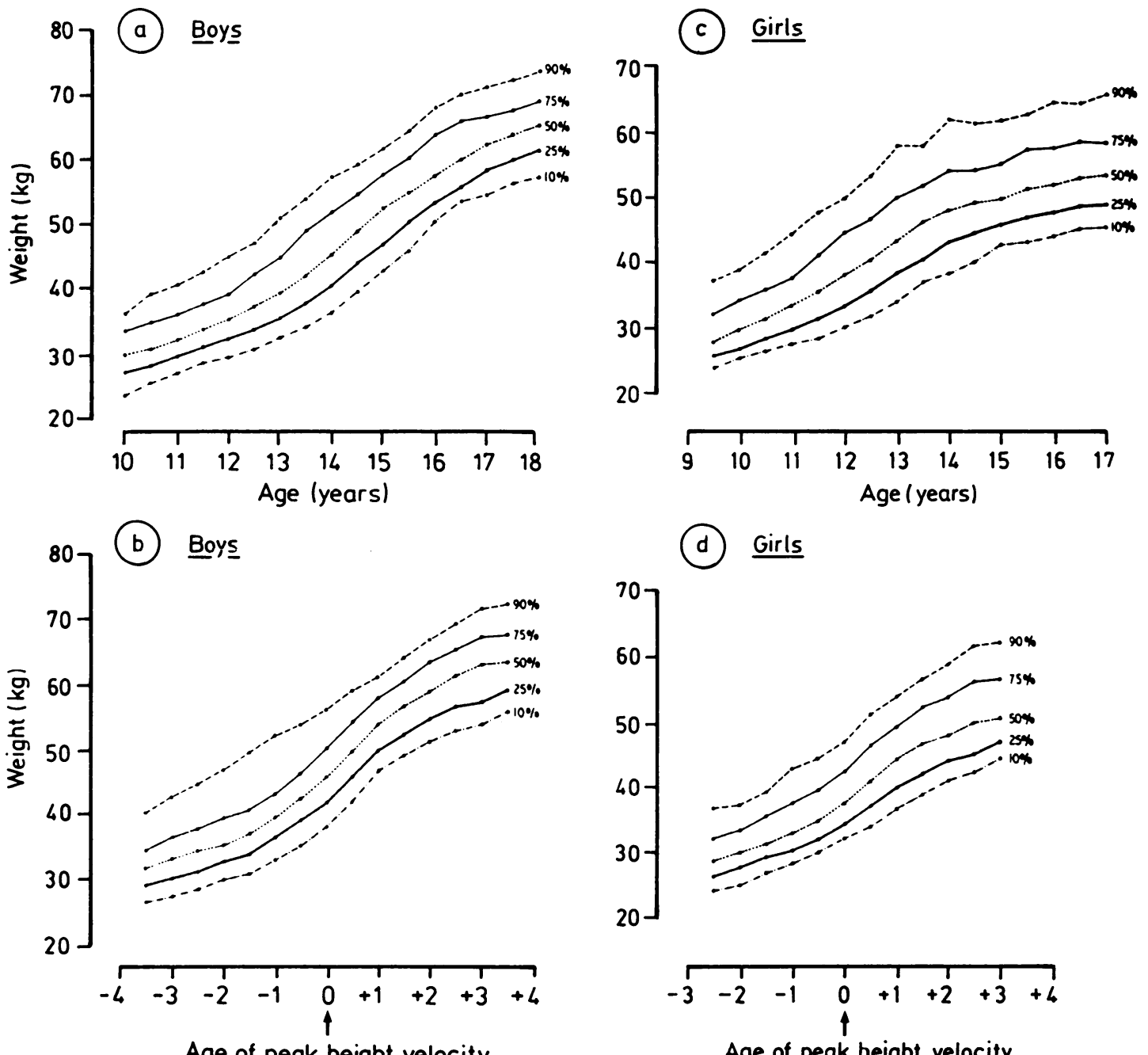

(d) Girls

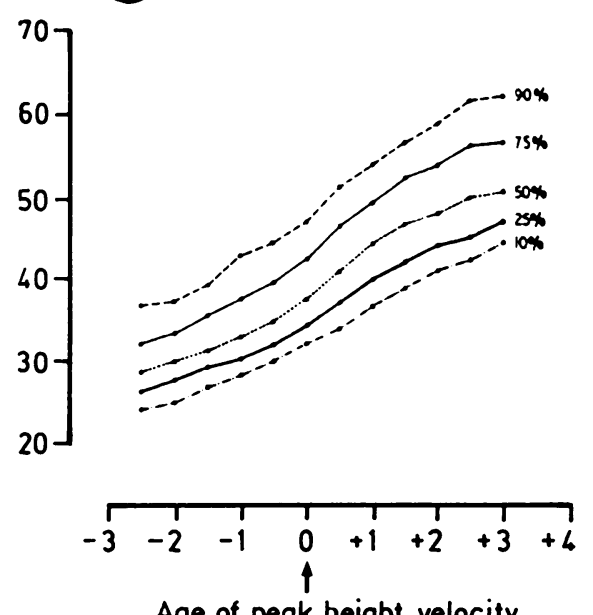

Age of peak height velocity

Fig 2 Centile curves for weight for girls and boys; $a$ and $c$ with respect to age and $b$ and $d$ relative to the age of peak height velocity.

in the way boys and girls grow at puberty. They show that girls develop earlier; for a short period are taller and heavier than boys; and that they slow down and stop growth on average two years before boys who end up on average $14 \mathrm{~cm}$ taller and, at age $17,8 \mathrm{~kg}$ heavier. Some of these comparisons between the sexes in terms of age and magnitude of the growth spurts for height and weight are shown in table 2 . The age when the average boy was growing at his fastest in height was very close to the age when he was increasing weight most rapidly. Girls, however, seemed to put on weight most rapidly later than the age of their peak height velocity.

\section{Discussion}

The practical difficulties encountered in arranging for one observer to see about 200 children three times a year for several years were vast. There was unavoidable inconsistency in the circumstances of measurement, interval between examination, timing of day, etc, which could influence the results. ${ }^{7}$ 


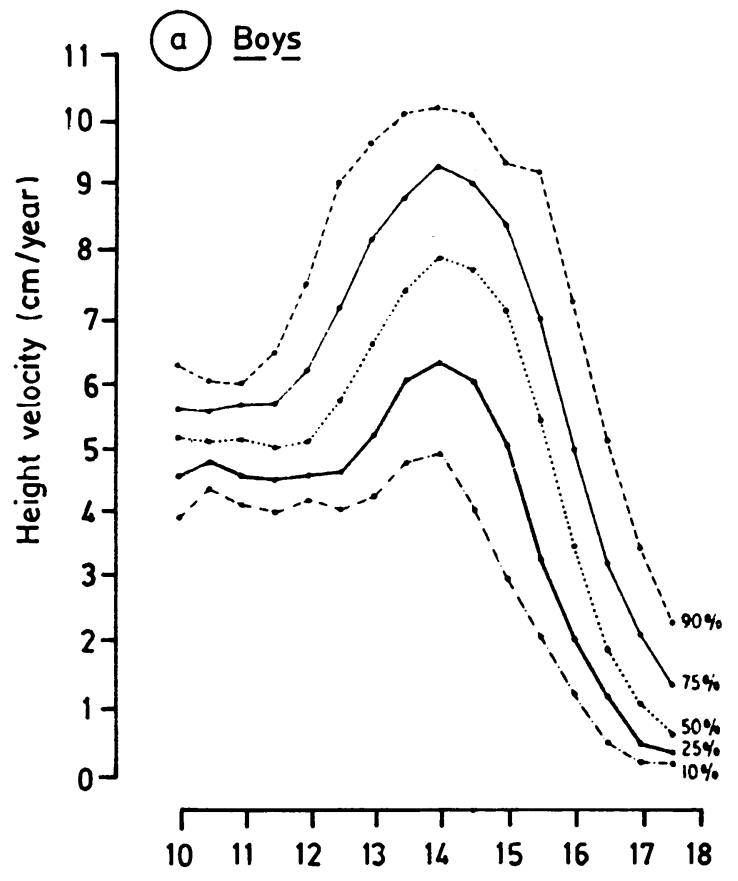

(c) Girls
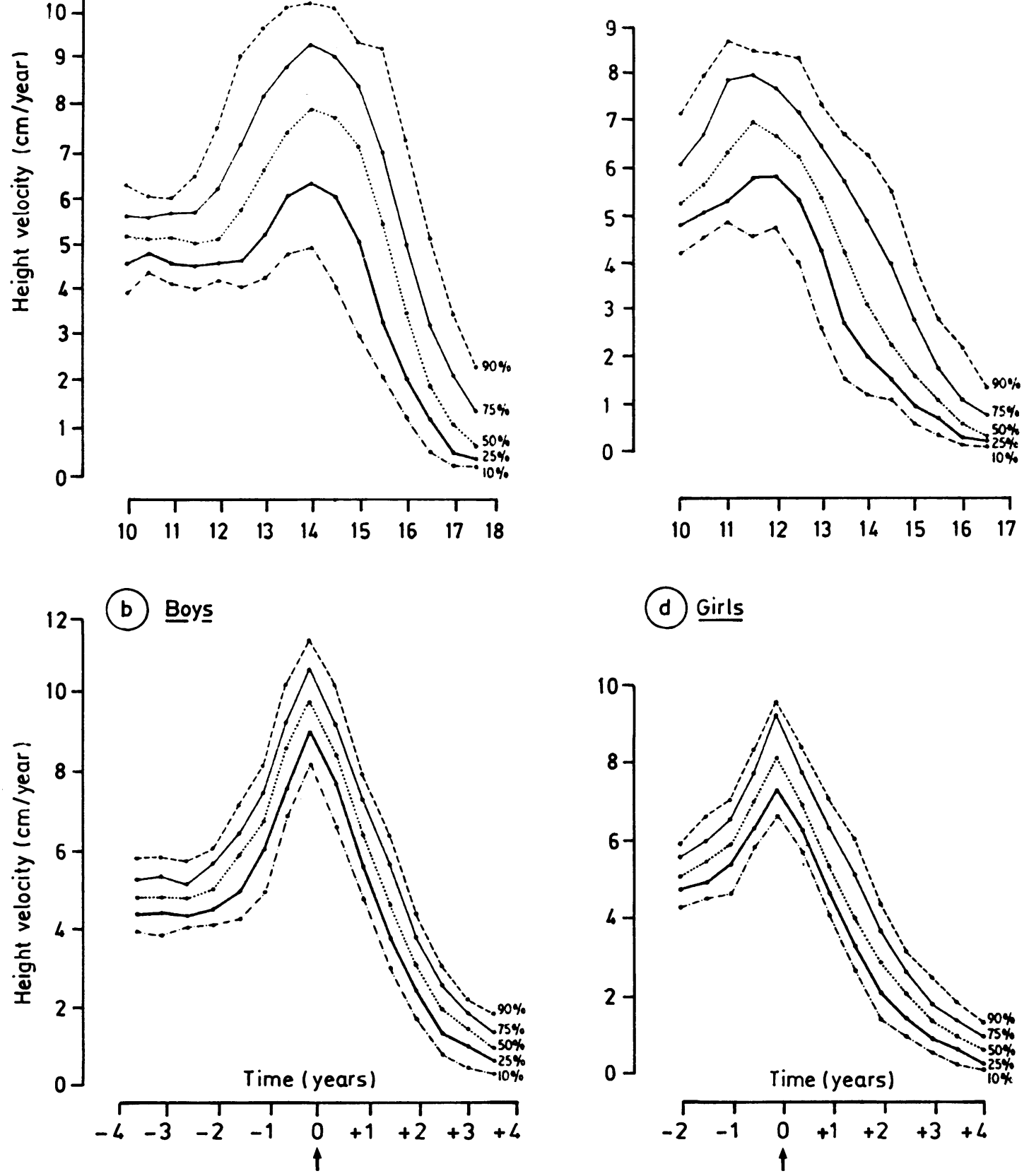

Age of peak height velocity
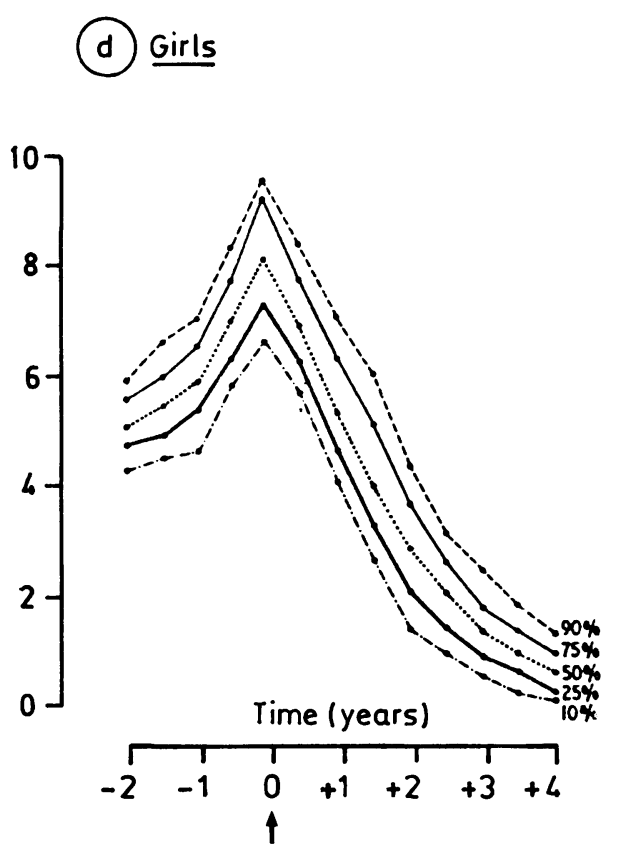

Age of peak height velocity

Fig 3 Centile curves for height velocity for girls and boys; $a$ and $c$ with respect to age and $b$ and $d$ relative to the age of peak height velocity. 

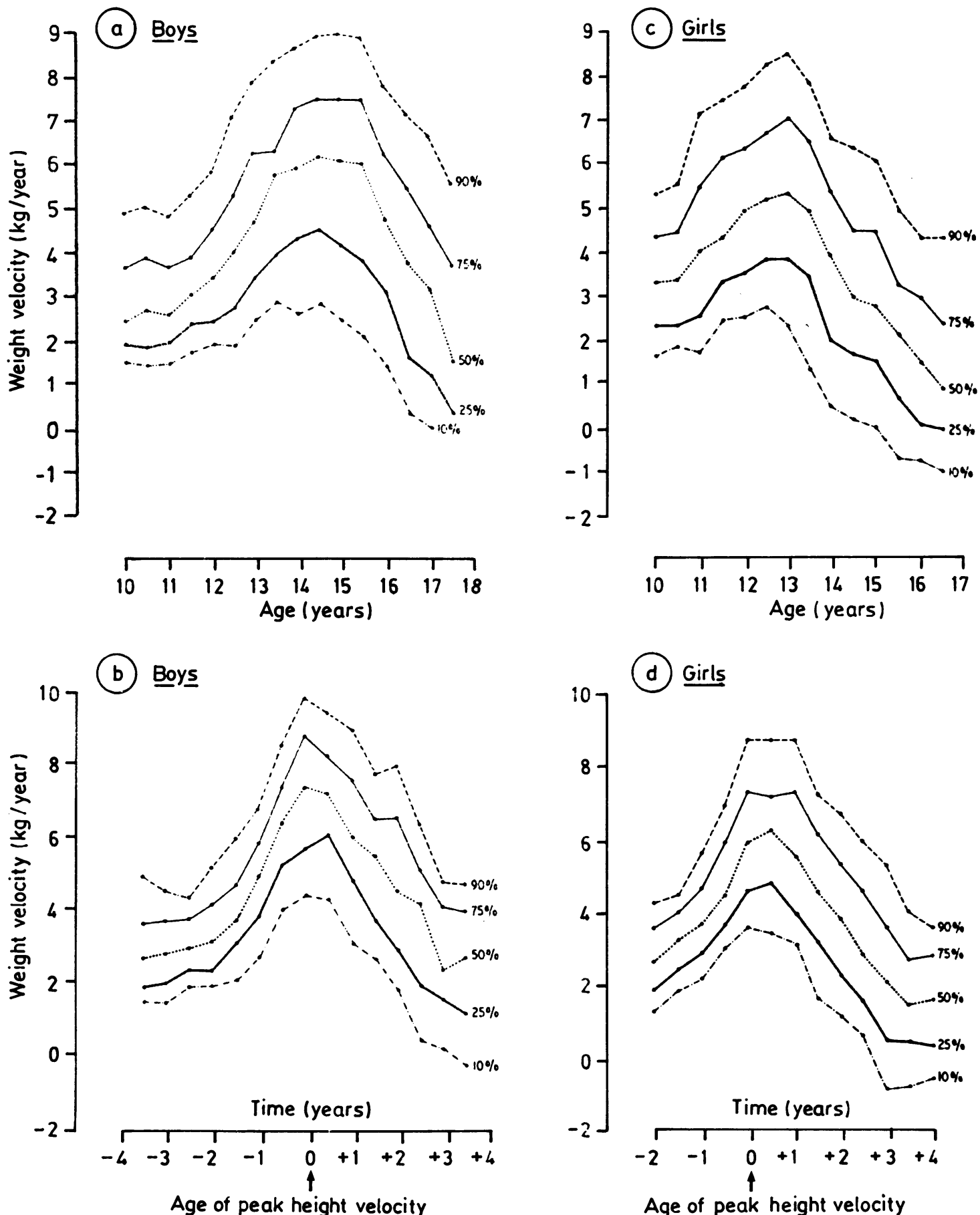

Fig 4 Centile curves for weight velocity for girls and boys; $a$ and $c$ with respect to age and $b$ and $d$ relative to the age of peak height velocity. 
Interpolated and extrapolated values are not scientifically ideal but were used only as a last resort. Omitting values could have introduced greater errors into the overall statistics.

Subjects were excluded, however, if they did not

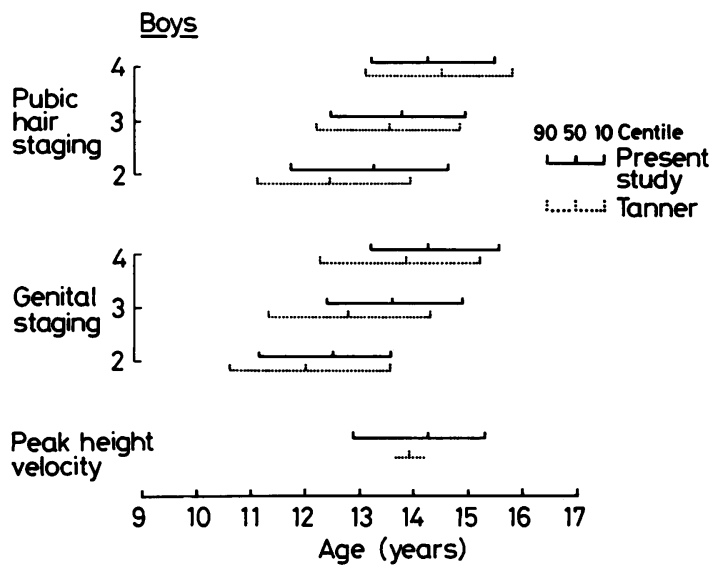

Fig 5 Ages of the stages of puberty for boys in this study compared with those of Tanner et al. ${ }^{13}$

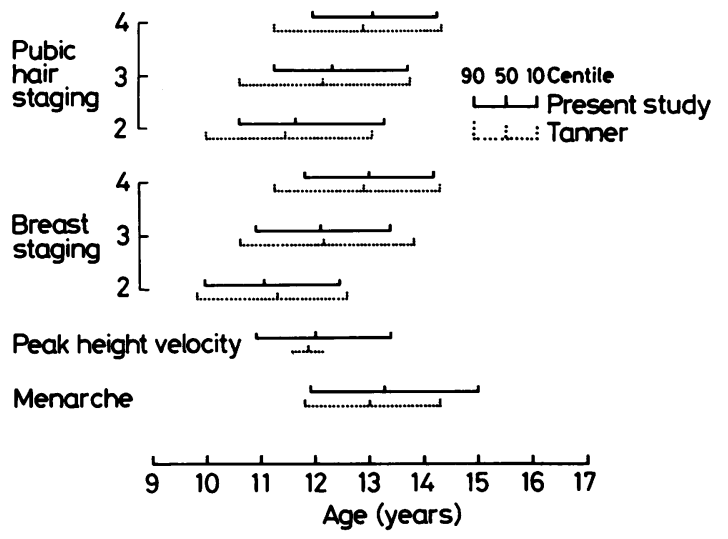

Fig 6 Ages of stages of puberty for girls in this study compared with those of Tanner et al. ${ }^{13}$ reach their peak height velocity during the course of the study or if they were beyond Tanner stage 2 breast or genital development when the first measurements were taken. It is arguable that these children represented the extent of the range of normality and should be included to give a true picture. It was nevertheless felt that subjects with such incomplete data should not be included.

Centile charts based on chronological age when used on their own can be misleading and some means of including data relevant to pubertal state is of importance. The use of centiles based on peak height velocity related ages not only provided a standard of comparison for the shape of individual distance and velocity curves, but gave a better indication of 'true physiological' centile placement. Age of peak height velocity was defined as the age at which the highest velocity value was obtained. As Preece $^{8}$ has reported there are various methods of fitting curves to data-for example, principal components ${ }^{9}$ and moving polynomial functions. ${ }^{10}$ Our measurements, however, were obtained at roughly four monthly intervals and this therefore sets the limit of our accuracy (whatever method of analysis is used). It would have been possible to calculate four monthly velocities - that is, the velocity between consecutive measurements rather than measurements about a year apart, but although in theory this would identify more precisely the shape of the velocity curve during the time of rapid change in practice it is liable to much greater error resulting from any inaccuracy in measurement or seasonal variation in growth rate. ${ }^{11}$

Although of academic value, the centiles presented, with age expressed relative to age at peak height velocity, are of limited clinical application as the age of peak height velocity is unlikely to have been reached at the relevant time of concern. Even before the age of peak height velocity is reached there can be a guideline by assuming an interval in time between the age of appearance of other pubertal features and peak height velocity. This is clearly approximate, and evidence from these

Table 2 Magnitude of the growth spurts for height and weight

\begin{tabular}{|c|c|c|c|c|c|c|c|}
\hline \multicolumn{4}{|c|}{ Peak height velocity } & \multicolumn{4}{|c|}{ Peak weight velocity } \\
\hline $\begin{array}{l}\text { Age in } \\
\text { years (SD) }\end{array}$ & Range & $\begin{array}{l}\text { Magnitude } \\
\text { in cm/year } \\
\text { (SD) }\end{array}$ & Range & $\begin{array}{l}\text { Age in } \\
\text { years }(S D)\end{array}$ & Range & $\begin{array}{l}\text { Magnitude } \\
\text { in kg/year } \\
\text { (SD) }\end{array}$ & Range \\
\hline \multicolumn{8}{|c|}{ Boys $(n=96)$} \\
\hline $14 \cdot 12(0 \cdot 92)$ & $11 \cdot 89-16 \cdot 44$ & $9.79(1.23)$ & $7 \cdot 00-13 \cdot 33$ & $14 \cdot 27(0.98)$ & $12 \cdot 26-16 \cdot 47$ & $8.64(1.72)$ & $4 \cdot 67-13 \cdot 67$ \\
\hline \multicolumn{8}{|c|}{ Girls $(n=102)$} \\
\hline $11.99(0.98)$ & $10 \cdot 07-14 \cdot 88$ & $8.14(1.07)$ & $4 \cdot 57-10 \cdot 10$ & $12 \cdot 78(1 \cdot 08)$ & $10 \cdot 07-15 \cdot 80$ & $7 \cdot 81(1.88)$ & $4 \cdot 60-13 \cdot 78$ \\
\hline
\end{tabular}


studies and others ${ }^{12}$ indicates that the earlier puberty occurs the shorter the time interval between the appearance of a feature of puberty and peak height velocity.

The reports of Tanner et al were based mainly on London schoolchildren in 1959 together with longitudinal data of the Harpenden Growth Study completed in the mid 1960s. ${ }^{1613}$ Comparisons of our results with these reports was interesting. Puberty in all stages occurred later in the boys in the present study (fig 5). The average age of onset of genital development was 0.5 years later than those in Tanner's study, ${ }^{6}$ first appearance of pubic hair about 0.8 years later, and the age of peak height velocity 0.35 years later. (In the report of the Harpenden Study in $1976,{ }^{13}$ however, somewhat different ages were given, pubic hair appearance being later and comparable with the findings of this report, whereas genital development was even earlier being slightly over a year younger than in our boys.) Interpretation of the first stage of genital development in boys (testicular growth) shows great variation from observer to observer and these differences may be misleading.

Differences in the ages of pubertal development in girls were far less pronounced (fig 6). The mean age of peak height velocity is almost identical in the studies and the mean age of menarche, although 0.25 years later than one of Tanner's reports from $1976^{6}$ was almost identical with the age given in another 1976 report. ${ }^{13}$ The ages of pubic hair and breast development were comparable.

The growth in height was different from that of the Tanner series in both boys and girls. The present group of boys and girls were slightly taller initially, but their final height was definitely taller on average: boys by $2.5 \mathrm{~cm}$, girls by $1.5 \mathrm{~cm}$. This seemed mainly due to the fact that growth had continued longer as the difference was not evident at the stages of more rapid growth.

Weight differences in this study were even more apparent but not in parallel ways in the boys and girls. The boys in this study were a little lighter throughout at comparable ages up to 16 , presumably due to changes of puberty being later, and were on average $2 \mathrm{~kg}$ lighter at age 15 . Ultimately, however, weight gain was greater and by 18 they were about 2 $\mathrm{kg}$ heavier on average than those of Tanner's standards. The Leeds girls were lighter at all ages than those in Tanner's study, they were less so prepubertally (averaging $1 \mathrm{~kg}$ lighter) but in mid puberty were about $3 \mathrm{~kg}$ lighter, and this difference was maintained despite the fact that these girls were ultimately slightly taller.

At school entry between the ages of 5 and 6 Leeds schoolchildren were of comparable height and weight to Tanner's standards..$^{14}$ It would seem that differences arise later, primarily related to pubertal growth.

A Swedish study in 1976 showed basically intermediary results between the present study and those of Tanner et al. ${ }^{5}$ There was little difference in the timing of peak height velocity in girls $(12.0$ years average) or menarche (average 13.0 years), though in boys it was fractionally earlier (14 years in the Swedish series compared with 14.25 years in the present study). The measurements of the Swedish children throughout the age range were slightly greater: boys being about $2 \mathrm{~cm}$ taller and $1-2 \mathrm{~kg}$ heavier, and girls $1-1.5 \mathrm{~cm}$ taller and 3-4 kg heavier than the Leeds children. Values were only reported up to age 16 , however, by which time our subjects seemed to be catching up in height and may have ended up taller through continuing to grow for a longer time.

A recent report, comparing French and English children born in 1953, found a lower body mass index in the French children. ${ }^{15}$ The present series of Leeds schoolchildren was more in line with the French children in that study. Another study that followed up children born in Newcastle in 1947 reported weights for boys and girls at ages 13, 14, and 15 that were very similar to this report. ${ }^{16}$ In terms of stature, however, the Newcastle children were considerably shorter: boys on average by $4.5-5 \mathrm{~cm}$ throughout, girls by $5 \mathrm{~cm}$ at 13 , but about $3.5 \mathrm{~cm}$ ultimately, puberty being a little later. Our study shows that adolescent children today have lower values weight for height than in the past.

Tanner and Davies recently produced standards for height (though unfortunately not for weight) for American children showing that in puberty they develop earlier (the peak height velocity for boys averaged 13.5 and for girls 11.5 ) and so are considerably taller than comparable British 14 year old boys and 12 year old girls. ${ }^{17}$ The average ultimate heights, however, for the present series of British boys and girls are about the same as those of the American children.

This paper shows the inevitable difficulties and limitations of longitudinal studies, but such studies are essential to elucidate the growth pattern of children as this is obscured by cross sectional studies. Numbers must of necessity be small if observations are to be consistent, reliable, and performed by a single observer; and the cooperation of the subjects must be maintained. When numbers are so small the significance of obtaining extremes of centile values may be questioned and also how representative this group is of the population as a whole. Different social and cultural backgrounds may influence growth patterns and we intend to 
investigate this further. The most important factor influencing growth in the teenage years, however, is the stage of pubertal development. Centiles based on peak height velocity related ages are therefore particularly useful for this age range.

We thank the staff and pupils of the schools that participated in this project; Mrs. Gillian Levell and Mrs Jyoti Anandjiwala for clerical help; Mrs Janet Walsh for typing the manuscript; and Rev W Sollom for devising the computer program and for his encouragement and advice. This study has been supported through the years by grants from the Children's Research Fund, Leeds Teaching Hospitals'. Special Trustees Fund, University of Leeds Research Fund, the Child Growth Foundation, and KabiVitrum Ltd.

\section{References}

1 Tanner JM, Whitehouse RH, Takaishi M. Standards from birth to maturity for height, weight, height velocity and weight velocity: British children, 1965. Arch Dis Child 1966;41:454-71, 613-25.

2 Tanner JM. Growth at adolescence (2nd ed.) Oxford: Blackwell Scientific Publications, 1962.

${ }^{3}$ Tanner JM, Hiernaux J, Jarman S. Growth and physique studies. In: Weiner JS, Laurie JA, eds. Human biology: a guide to field methods. Oxford: Blackwcll Scientific Publications, 1969:8.

${ }^{4}$ Rao DH, Sastry JG. Day to day variation in body weights of children. Ann Hum Biol 1976;3:75.

5 Karlberg P, Taranger J, Engstrom I, Lichtenstein H, SvennbergRedegren I. The somatic development of children in a Swedish urban community. Acta Paediatr Scand 1976: suppl 258:9.

6 Tanner JM, Whitehouse RH. Clinical longitudinal standards for height, weight, height velocity, weight velocity and stages of puberty. Arch Dis Child 1976;51:170-9.

7 Buckler JMH. Variations in height throughout the day. Arch Dis Child 1978:53:762.

${ }^{x}$ Preece MA. Analysis of the human growth curve. Postgrad Med J 1978;54(suppl 1):77-89.

${ }^{9}$ Berkey CS, Kent RL Jr. Longitudinal principal components and non-linear regression models of early childhood growth. Ann Hum Biol 1983;10:523-36.

${ }^{10}$ Kemper HCG, Storm-Van Essen L, Verschuur R. Height velocity in a group of teenage boys. Ann Hum Biol 1985;12: 545-9.

1 Marshall WA, Swan AV. Seasonal variation in growth rates of normal and blind children. Hum Biol 1971;43:502-16.

12 Onat T, Ertem B. Adolescent female height velocity: relationships to body measurements, sexual and skelctal maturity. Hum Biol 1974:46:199-217.

13 Tanner JM, Whitehouse RH, Marubini E, Resele LF. The adolescent growth spurt of boys and girls of the Harpenden Growth Study (1976). Ann Hum Biol 1976;3:109-26.

${ }^{14}$ Buckler JMH. Are Tanner growth charts applicable to children at school entry in Leeds? Arch Dis Child 1985;60:1188-91.

15 Stark O, Peckham CS, Ades A. Weights of British and French children. Lancet 1986;i:862.

${ }^{16}$ Miller FJW, Billewicz WZ, Thomson AM. Growth from birth to adult life of 442 Newcastle upon Tyne schoolchildren. British Journal of Preventive and Social Medicine 1972;26:224-30.

17 Tanner JM, Davies PSW. Clinical longitudinal standards for height and height velocity for North American children. J Pediatr 1985;107:317-29.

Correspondence to Dr JMH Buckler, University Department of Paediatrics and Child Health, D Floor, Clarendon Wing, Leeds General Infirmary, Belmont Grove, Leeds LS2 9NS.

Received 8 July 1987 